\title{
Mutations in the mitochondrial cysteinyl-tRNA synthase gene, CARS2, lead to a severe epileptic encephalopathy and complex movement disorder
}

\author{
Curtis R Coughlin II, ${ }^{1}$ Gunter H Scharer, ${ }^{1,2,3}$ Marisa W Friederich, ${ }^{1}$ Hung-Chun $\mathrm{Yu}_{1}{ }^{1}$ \\ Elizabeth A Geiger, ${ }^{1}$ Geralyn Creadon-Swindell, ${ }^{1}$ Abigail E Collins, ${ }^{4}$ \\ Arnaud V Vanlander, ${ }^{5}$ Rudy Van Coster, ${ }^{5}$ Christopher A Powell, ${ }^{6}$ \\ Michael A Swanson, ${ }^{1}$ Michal Minczuk, ${ }^{6}$ Johan L K Van Hove, ${ }^{1}$ Tamim H Shaikh ${ }^{1,2}$
}

\begin{abstract}
- Additional material is published online only. To view please visit the journal online (http://dx.doi.org/10.1136/ jmedgenet-2015-103049)
\end{abstract}

For numbered affiliations see end of article.

\section{Correspondence to} Dr Tamim H Shaikh,

Department of Pediatrics, Section of Genetics,

University of Colorado School of Medicine, Aurora, CO 80045, USA;

tamim.shaikh@ucdenver.edu

$\overline{\mathrm{CRC} \text { and GHS }}$ contributed equally.

Received 29 January 2015 Revised 25 February 2015 Accepted 26 February 2015 Published Online First 18 March 2015

\section{SLinked}

- http://dx.doi.org/10.1136/ jmedgenet-2014-102355

\section{ABSTRACT}

Background Mitochondrial disease is often suspected in cases of severe epileptic encephalopathy especially when a complex movement disorder, liver involvement and progressive developmental regression are present. Although mutations in either mitochondrial DNA or POLG are often present, other nuclear defects in mitochondrial DNA replication and protein translation have been associated with a severe epileptic encephalopathy.

Methods and results We identified a proband with an epileptic encephalopathy, complex movement disorder and a combined mitochondrial respiratory chain enzyme deficiency. The child presented with neurological regression, complex movement disorder and intractable seizures. A combined deficiency of mitochondrial complexes I, III and IV was noted in liver tissue, along with increased mitochondrial DNA content in skeletal muscle. Incomplete assembly of complex $V$, using blue native polyacrylamide gel electrophoretic analysis and complex I, using western blotting, suggested a disorder of mitochondrial transcription or translation. Exome sequencing identified compound heterozygous mutations in CARS2, a mitochondrial aminoacyl-tRNA synthetase. Both mutations affect highly conserved amino acids located within the functional ligase domain of the cysteinyl-tRNA synthase. A specific decrease in the amount of charged mt-tRNA ${ }^{\text {Cys }}$ was detected in patient fibroblasts compared with controls. Retroviral transfection of the wild-type CARS2 into patient skin fibroblasts led to the correction of the incomplete assembly of complex $\mathrm{V}$, providing functional evidence for the role of CARS2 mutations in disease aetiology.

Conclusions Our findings indicate that mutations in CARS2 result in a mitochondrial translational defect as seen in individuals with mitochondrial epileptic encephalopathy.

\section{INTRODUCTION}

Mitochondrial dysfunction is a common cause of human disease with an incidence of 1:5000 to 1:10 000 live births. ${ }^{1}$ Despite the high frequency of disease, a majority of patients remain without a genetic diagnosis. Mitochondrial disease has been associated with mutations in 13 mitochondrialencoded genes and in $>200$ nuclear-encoded genes. $^{2}$ Furthermore, there are $>1000$ nuclear genes that encode mitochondrial-targeted proteins, providing a large number of probable candidate genes as the cause of mitochondrial dysfunction. ${ }^{3}$ The large number of candidate genes and heterogeneous manifestations of disease are the main impediment to the genetic diagnosis. However, recent developments in high-throughput sequencing have significantly increased the detection of mutations in nuclear-encoded genes associated with mitochondrial disease. ${ }^{4-6}$

Despite the increased utility of genetic testing, providing proof of pathogenicity of novel variants remains challenging and mitochondrial functional studies remain an integral part of the evaluation. The results of functional studies may help narrow down potential candidate genes to a specific gene function as well as provide a means to validate genetic results. Decreased activity of respiratory chain enzymes or altered oxidative phosphorylation coupling can illustrate mitochondrial dysfunction. Isolated deficiency of the activity of a single respiratory chain enzyme is typically the result of genetic alterations in structural subunits or assembly proteins for respiratory chain complexes. Combined deficient activity of multiple respiratory chain enzymes may be caused by defects in proteins required for mitochondrial DNA (mtDNA) maintenance, transcription or translation.

Although the clinical findings in mitochondrial disease are heterogeneous, central nervous system involvement is common, often manifesting as neurological regression or movement disorders. Various epileptic conditions have been well described in patients with mitochondrial disease. ${ }^{7-9}$ Severe mitochondrial epileptic encephalopathies are most commonly associated with myoclonic epilepsy with ragged red fibres and Alpers' syndrome. Patients with Alpers' syndrome often present in infancy with cortical atrophy and prominent epilepsy, which may evolve into intractable epilepsy, ${ }^{10}{ }^{11}$ and a deficiency of respiratory chain enzymes is prominently present in liver, whereas other tissues, such as skeletal muscle, can be normal. ${ }^{12}$ Mutations in the polymerase- $\gamma$ gene, $P O L G$, account for the majority of cases of Alpers' syndrome. ${ }^{13} 14$ Other genes involved in mitochondrial replication and translation have also been associated with mitochondrial epileptic encephalopathies. 
We describe a child with a severe epileptic encephalopathy, complex movement disorder and a combined respiratory chain enzyme deficiency in whom we identified mutations in a gene involved in mitochondrial translation. Multiple mitochondrial respiratory chain enzyme deficiencies in liver and decreased synthesis of mtDNA-encoded subunits were consistent with a defect in either mitochondrial transcription or translation. Using trio-based exome sequencing, we identified compound heterozygous mutations in CARS2, a mitochondrial cysteine-specific aminoacyl-tRNA synthetase, consistent with the patient's phenotype and the mitochondrial respiratory chain enzyme analysis.

\section{Subject}

The infant, the second child of non-consanguineous parents of Scandinavian ethnicity, presented at 5 weeks of age with episodes of opisthotonus and feeding difficulties resulting in failure to thrive for which he received a gastrostomy tube and Nissen fundoplication. His early clinical course was marked for a delay in acquiring developmental milestones, and he developed hypotonia and abnormal movements. His highest level of developmental function included ambulation with the assistance of a walker, hitting a toy and babbling. He declined in function over a 3-year period with regression usually associated with infections and resulting in the loss of skills such as rolling over, reaching and grasping. He developed a complex movement disorder with chorea, dystonia including oculogyric episodes, myoclonus, startle myoclonus and developed microcephaly.

At 3 year 10 months, he developed medically refractory complex partial status epilepticus, with severe background slowing, multifocal epileptiform discharges, frequent focal myoclonic and complex partial seizures. These seizures were unresponsive to midazolam and pentobarbital infusions, the ketogenic diet and multiple antiseizure medications. He was discharged in complex partial status epilepticus and has remained in this condition for $>5$ years. Myoclonus remained frequent, but his chorea and dystonia resolved. He had central and obstructive sleep apnoea and swallowing dysfunction. He developed osteoporosis and presented spontaneous fractures of both humeri at age 6 years. Presently, he is alert, has frequent myoclonus of his distal limbs or mouth, is severely hypotonic and does not have antigravity movements of his limbs or head. He is areflexic and has no purposeful or elicited eye movements on oculocephalic manoeuvre. He communicates with family members using an augmented communication device by moving a finger or foot to activate a button. He receives a very low caloric diet via G-tube to avoid excessive weight gain.
Brain MRI showed progressive atrophy of the cortex and, more prominently, of the white matter with focal increased T2 signal in cortex and white matter, a very thin corpus callosum and atrophic cerebellar vermis (figure 1). He developed multifocal epileptiform discharges on EEG most prominent over the posterior quadrant, with slowing posteriorly and, at present, continuous multifocal high-amplitude epileptic discharges on EEG. Serum lactate was increased in $50 \%$ of samples obtained, up to $5.8 \mathrm{mM}$ maximum. Lactate in spinal fluid was increased at 2.6-3 mM with a normal lactate/pyruvate ratio of 12 and 13, respectively. Serum alanine was mildly elevated at $511 \mu \mathrm{M}$ and cerebrospinal fluid (CSF) alanine was mildly elevated at 45 and $52 \mu \mathrm{M}$ (normal range $13-48 \mu \mathrm{M}$ ). His albumin has been low frequently, and almost continually since age 6 years (average of $3.1 \mathrm{~g} / \mathrm{dL}$, age-related normal range $3.7-5.6 \mathrm{~g} / \mathrm{dL})$. The coenzyme $Q$ level in serum was normal $(0.67 \mathrm{mg} / \mathrm{L}$, normal range $0.4-1.19 \mathrm{mg} / \mathrm{L})$. Other liver function tests such as bilirubin, transaminases, ammonia and clotting factors have been normal and renal function has been normal including absence of proteinuria. Biopsies for mitochondrial evaluation in skeletal muscle, liver and skin were obtained at 3 year 10 months. The liver showed mild microvesicular steatosis with normal mitochondrial ultrastructure, and the skeletal muscle had normal histology. He had normal enzyme activities for biotinidase and pyruvate dehydrogenase, and normal molecular investigations for mitochondrial bioenergetic disorders included mtDNA point mutations and deletions in leucocytes, complete mtDNA sequencing in skeletal muscle and sequencing of POLG1, TK2, ANT1, DGUOK, SUCLA2, POLG2, MPV17, TWINKLE (C10orf2), RRM2B and TIMM8A. His karyotype was normal, and array-based comparative genomic hybridisation was negative for clinically significant copy number variations.

\section{METHODS}

\section{Respiratory chain enzyme analysis}

Respiratory chain enzyme activities for complexes I, II, II+III, III, IV and citrate synthase (CS) were assayed in post $600 \mathrm{~g}$ supernatants spectrophotometrically on a Cary 300 spectrophotometer at $30^{\circ} \mathrm{C}$ in cultured skin fibroblasts and in skeletal muscle as described with some modifications. ${ }^{15} 16$ For complexes I, II, II+III and CS, enzyme activities were calculated as initial rates $(\mathrm{nmol} / \mathrm{min})$, and for complexes III and IV as firstorder rate constants. All activities were normalised to the total protein content in each sample and expressed as ratios over the activity of CS and of complex II. The natural log of the activities and of the ratios in control samples was normally distributed, and the results were thus expressed as Z-scores. The

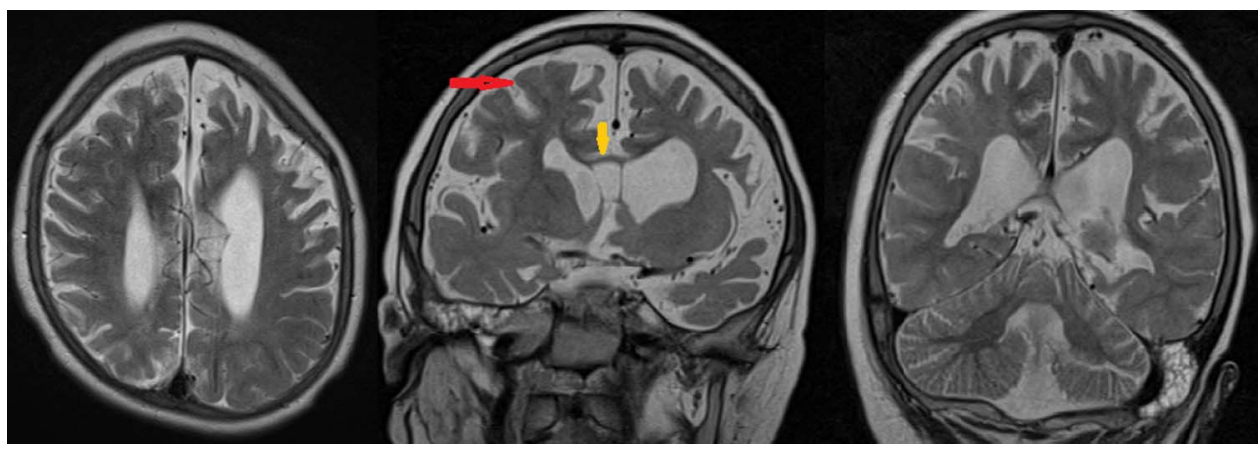

Figure 1 Brain MRI. MRI of the brain at age 6 years showing axial and coronal images on a T2-weighted sequence. Global atrophy of the cerebrum and the cerebellar vermis with secondary ex vacuo dilatation of the lateral and third ventricle is seen. The cerebral white matter shows atrophy. A red arrow shows a deep sulcus representative of the cerebral atrophy, and the orange arrow illustrates the very thin corpus callosum. 
normal ranges were derived from 25 muscle controls, 16 liver controls and 20 control fibroblasts.

The integrity of the assembly of complexes I, II, IV and V was evaluated using blue native polyacrylamide gel electrophoretic (BN-PAGE) analysis followed by in-gel activity stain in skeletal muscle and in a cultured skin fibroblast pellet using a previously published method. ${ }^{17}{ }^{18}$ This method can identify defects in mitochondrial transcription and translation by showing bands of incompletely assembled complex V as reported earlier. ${ }^{19}$

\section{DNA extraction}

High-quality, unfragmented genomic DNA (A260/A280 $\geq 1.8$ and A260/A230 $\geq 1.9$ ) was extracted from whole blood obtained from the subject and his parents using a FujiFilm DNA Extraction Robot, from FujiFilm Medical Systems (Stamford, Connecticut, USA) using QuickGeneR DNA whole blood kit L, from Kurabo Industries (Osaka, Japan), and using the salting out method from QIAGEN following the manufacturer's instructions.

\section{Exome sequencing and data analysis}

Exome sequencing on the subject and his parents was performed using Nimblegen 44Mb SeqCap EZ Exome V.2.0 (Roche Nimblegen, Madison, Wisconsin, USA) followed by sequencing on an Illumina HiSeq 2000 (Illumina, San Diego, California, USA). Approximately 50 million, $90 \mathrm{bp}$, paired-end reads were obtained from each individual sequenced. On average, over $50 \times$ coverage was obtained from the subject and his parents. Sequence reads were analysed using well-established mapping and variant detection software (details provided in online supplementary methods). The sequence data from the patient and parents were used to test for causal variants as previously described. ${ }^{20}$

\section{PCR and Sanger sequencing}

Variants identified in CARS2 (NM_024537.2, ENST00000 257347) were further validated by Sanger sequencing in the subject and his parents. Primers were designed to amplify and sequence exons 6 and 7 of CARS2 where the identified sequence variants are located in the proband. Primers were designed to amplify and sequence all exon and intron boundaries of CARS2 in the additional 15 subjects. Genomic DNA (100 ng) was amplified using PCR, with reactions and conditions as follows: Promega GoTaq Hot Start' kit (Promega, Madison, Wisconsin, USA) with $1 \times$ Master Mix and $400 \mathrm{nM}$ of each primer. The PCR began with an initial cycle at $95^{\circ} \mathrm{C}$ for $3 \mathrm{~min}$, followed by 30 cycles of $94^{\circ} \mathrm{C}$ for $30 \mathrm{~s}, 60^{\circ} \mathrm{C}$ for $30 \mathrm{~s}$ and $72^{\circ} \mathrm{C}$ for $1 \mathrm{~min}$, finishing with extension at $72^{\circ} \mathrm{C}$ for $5 \mathrm{~min}$. Amplified PCR products were sequenced using the PCR primers as sequencing primers on an ABI (Life Technologies, Carsbad, California, USA) PRISM 3730xl at a commercial Clinical Laboratory Improvement Amendments (CLIA)-certified sequencing facility.

\section{Protein analysis}

For SDS-PAGE, $5 \mu \mathrm{g}$ of protein was separated on a $5-20 \%$ gradient polyacrylamide gel with sodium dodecyl sulfate followed by western blotting, and detection using the appropriate primary antibody, followed by incubation with horseradish peroxidase (HRP)-conjugated secondary antibody, and visualised by chemiluminescence. Assembly of mitochondrial complexes was further evaluated by western blotting after BN-PAGE of $10 \mu \mathrm{g}$ of mitochondrial protein, and probed with an antibody against the complex I subunit NDUFS2 (Mitosciences, MS114), a subunit that incorporates into the early stages of complex I assembly. The full-length amino acid sequences of human CARS2 and the Escherichia coli cysteinyl-tRNA syntethase$\mathrm{tRNA}^{\mathrm{Cys}}$ complex were aligned and the relative positions of homologous residues were modelled using the crystal structure of the E. coli enzyme (1U0B). ${ }^{21}$

\section{Aminoacylation assay}

Aminoacylation of mt-tRNA-Cys was analysed as described previously. ${ }^{22}$ Briefly, total RNA was extracted from fibroblasts using Trizol reagent (Life Technologies) following the manufacturer's instructions, with the final pellet resuspended in $10 \mathrm{mM} \mathrm{NaOAc}$ at $\mathrm{pH} 5.0$ and kept at $4^{\circ} \mathrm{C}$ to preserve the aminoacylation state. For the deacylated control, the pellet was resuspended in $200 \mathrm{mM}$ Tris- $\mathrm{HCl}$ at $\mathrm{pH} 9.5$ and incubated at $75^{\circ} \mathrm{C}$ for $5 \mathrm{~min}$, followed by RNA precipitation and resuspension in $10 \mathrm{mM}$ $\mathrm{NaOAc}$ at $\mathrm{pH}$. Next, $15 \mu \mathrm{g}$ of RNA was separated on a $6.5 \%$ polyacrylamide gel (19:1 acrylamide:bisacrylamide) containing $8 \mathrm{M}$ urea in $0.1 \mathrm{M} \mathrm{NaOAc} \mathrm{pH} 5.0$ at $4^{\circ} \mathrm{C}$ and electroblotted (Bio-Rad, Trans-Blot Cell) onto a nylon transfer membrane (Hybond, GE). Following UV-crosslinking, the membrane was hybridised with appropriate radiolabelled riboprobes, washed and imaged using a PhosphorImager.

\section{Correction studies}

The full-length CARS2 cDNA in vector pOTB7 was obtained from Open Biosystems (Catalog MHS1011-60885 Accession (genbank): BC007220). The cDNA fragment was excised using EcoRI and XhoI and subcloned into the pCHAC-MCSIRES-mWasabi vector of the Gryphon retrovirus expression system, which contains the $5^{\prime} \mathrm{LTR}$, the packaging signal and the $3^{\prime}$ LTR with the gene inserted in the multicloning site followed by an IRES and a mWasabiGFP protein (Allele Biotechnology, San Diego, California, USA). The vector was transfected into the Gryphon amphotrophic packaging cells by electroporation using the Amaxa Nucleofector II electroporation system (Lonza Group, Basel, Switzerland). The resulting viral supernatant used for transduction of the patient cultured skin fibroblasts contained $4 \mu \mathrm{g} / \mu \mathrm{L}$ polybrene. More than $75 \%$ of fibroblasts showed active fluorescence from the WasabiGFP showing good transfection efficiency. The effect of the introduction of the native CARS2 cDNA construct was followed by BN-PAGE gel analysis.

\section{Additional patient samples}

To identify the frequency of CARS2 mutations in patients with mitochondrial translation defects, samples from 15 other patients were identified. These patients each had a combined respiratory chain enzyme deficiency, fragmented complex $\mathrm{V}$ on BN-PAGE analysis and normal mtDNA analysis, thus indicating a defect in either mitochondrial transcription or translation. ${ }^{19}$ Primers were designed to amplify and sequence all exons and exon-intron boundaries of CARS2 and subjects were Sanger sequenced after PCR amplification.

\section{RESULTS}

\section{Respiratory chain enzyme analysis}

We observed a combined deficiency of the activities of complex I and III and low activity of complex IV (not statistically significant) in the liver of the subject (see online supplementary table S1). In muscle, there was a tendency towards low activity for complexes I and IV, which did not reach statistical significance. This may be due to a compensatory amplification of mtDNA as a result of mitochondrial dysfunction. This is supported by the significant elevation of mtDNA copy number in muscle at $315 \%$ 
of age and tissue-matched controls (value: 5506; control: 1746 \pm 361 ). In fibroblasts, complex IV activity tended to be low as well. The BN-PAGE gel analysis with in-gel activity staining showed the presence of additional bands reflecting incomplete assembly of complex $\mathrm{V}$ present in both skeletal muscle and cultured skin fibroblasts (figure 2A, B). Such bands of lower molecular mass in complex $\mathrm{V}$ have been shown to occur in patients with defects in complex $\mathrm{V}$ assembly, with mtDNA depletion, or in defects in mitochondrial transcription or translation. ${ }^{19}$ The combined deficiency in liver indicates that the deficiency is not limited to complex V assembly, and a western blot with an antibody against NDUFS2 indicated incomplete assembly of complex I (see online supplementary figure S1). The high mtDNA copy number in skeletal muscle excludes mtDNA depletion syndrome, thus indicating that the defect affects mitochondrial transcription, RNA processing or translation. A large number of genes are involved in mitochondrial RNA transcription and processing and in the mitochondrial translation process, thus making an exome analysis approach preferable. $^{23-29}$

\section{Exome sequencing}

Exome sequencing was performed in the proband and the unaffected parents. The downstream analysis was focused on non-synonymous coding variants, coding InDels and variants affecting splice sites. We first filtered out common variants present in dbSNP and 1000 Genomes data. Parental exome sequencing data were used to identify possible pathogenic variants under various inheritance models including dominant (de novo mutations) and recessive (compound heterozygous, homozygous and X-linked hemizygous mutations) models. This resulted in the identification of three candidate genes, DMXL1, CCDC120 and CARS2, which were considered for further analysis (see online supplementary table S2).

Using a recessive inheritance model, we identified two heterozygous, non-synonymous sequence variants in the mitochondrial cysteinyl-tRNA synthetase, CARS2, that were considered potentially pathogenic. The patient inherited an in-frame deletion
c.649_651delGAG (p.Glu217del) from his father and a missense mutation c.752C $>\mathrm{T}$ (p.Pro251Leu) from his mother in CARS2. Sanger sequencing confirmed the presence of both the mutations in the patient and inheritance of one mutation from each parent, respectively. Both mutations affect highly conserved residues (figure 3) in the cysteinyl-tRNA synthetase located within the conserved functional ligase domain (Cys-tRNA/ MSH-ligase). The missense mutation Pro251Leu is predicted deleterious by bioinformatics software (Polyphen2, score 1.0). The Pro251 missense mutation was modelled on a homologous structure from E. coli (1U0B). The deleted amino acid Glu297 could not be modelled because it is located in a nine amino acid region that has no homology in the bacterial enzyme. Pro251 is located in the CP domain near several important residues including His254, which is involved in hydrogen bonding with RNA phosphates; Trp253, which is involved in tRNA ${ }^{\text {Cys }}$ substrate binding; and a conserved group of four hydrophobic amino acids (Ile169, Trp242, Thr166, Val121) neighbouring Pro251 in the 3D structure. ${ }^{21}$ This suggests that the mutation causes a structural change in an important region of CARS2 (see online supplementary results, figure S2 and S3).

CARS2 (NM_024537.2) contains 15 exons (transcript length $1.88 \mathrm{~kb}$ ) encoding a mitochondrial-targeted (62 AA mitochondriatargeting peptide) protein with 564 amino acid residues (NP 078813.1; CCDS9514.1). At the time of analysis, defects in CARS2 had not been reported or associated with a specific phenotype. However, this finding was consistent with the pathophysiology of other reported aminoacyl-tRNA synthetase (ARS) defects, where mutations are mostly clustered in conserved regions of the core catalytic domain and the tRNA anticodon-binding domain. ${ }^{30}$ Thus, CARS2 was considered the best candidate for a role in disease aetiology prompting further investigation.

\section{Mitochondrial tRNA aminoacylation analysis}

Functional impact of the CARS2 mutations on the mitochondrial cysteinyl-tRNA was assessed by high-resolution northern blotting of RNA isolated from patient primary skin fibroblasts. The use of low $\mathrm{pH}$ throughout the procedure allows for distinction
A Muscle

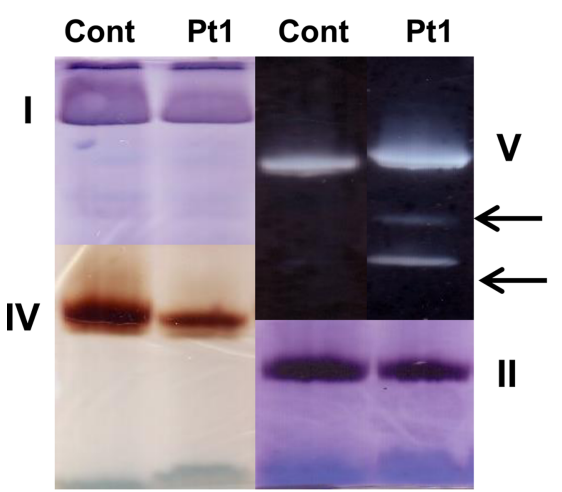

B Fibroblasts

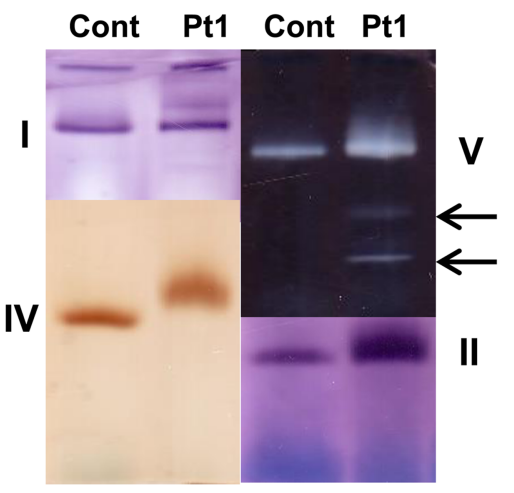

C

Fibroblasts correction studies

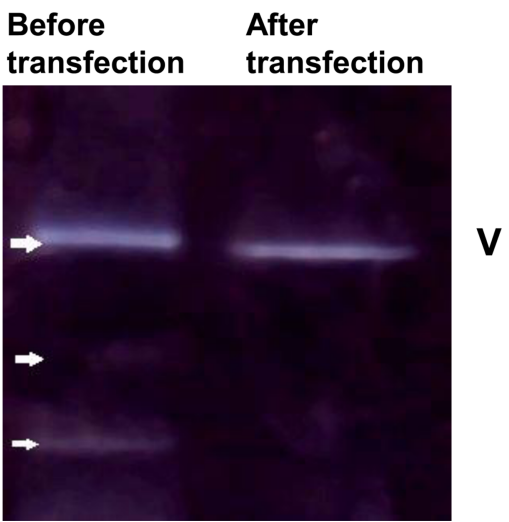

Figure 2 Characterisation of biochemical and molecular defects in subject cells and correction studies. Blue native polyacrylamide gel analysis of mitochondrial respiratory chain complexes I-V with in-gel activity staining, assayed in skeletal muscle (A) and cultured skin fibroblasts (B) from the proband compared with a healthy control. In both tissues from the proband, bands with a lower molecular mass were seen following staining for complex V indicating the presence of incompletely assembled complex V. (C) Correction studies by transfection of wild-type CARS2 into patient-cultured skin fibroblasts. Before transfection, an additional lower band and a faint middle band are seen, representing incomplete assembly of complex V. After transfection of the cultured skin fibroblasts with the wild-type CARS2 CDNA, these additional bands representing incompletely assembled complex $\mathrm{V}$ were no longer present. 
A

\section{Father}

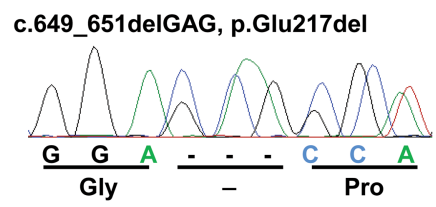

wt

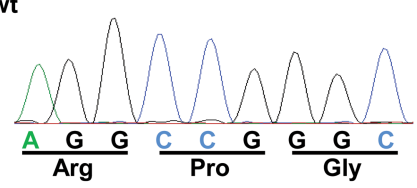

Mother

wt

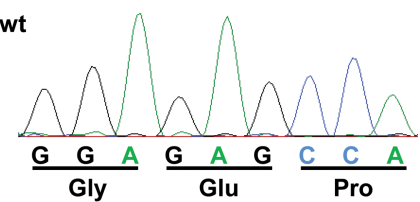

c.752C>T, p.Pro251Leu

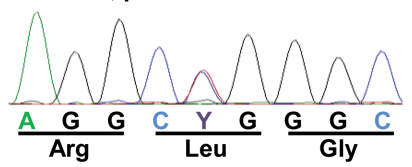

Patient
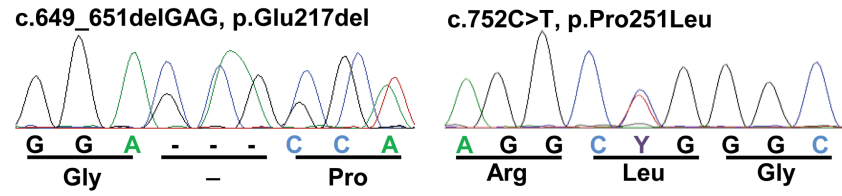

B
Human (NP_078813.1)

Gorilla (XP_004054781.1)

Cow (NP 001039409.1)

Dog (XP_534184.2)

Mouse (NP_077210.1)

Rat (NP $0 \overline{0} 1171155.1$ )

Xenopus (NP_001004887.2)

Zebrafish (XP 682732)

Fruitfly (NP_- 10930.1 )

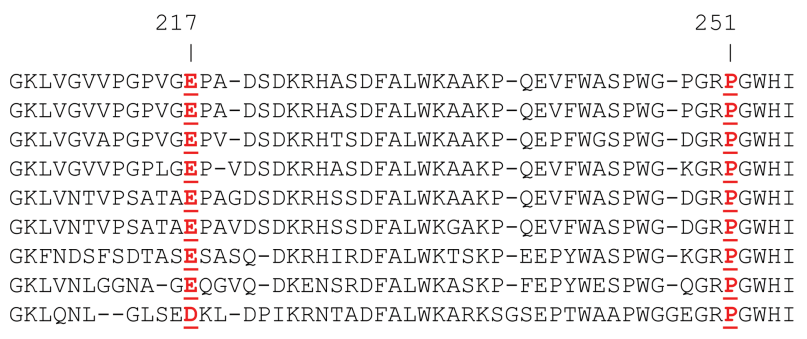

C

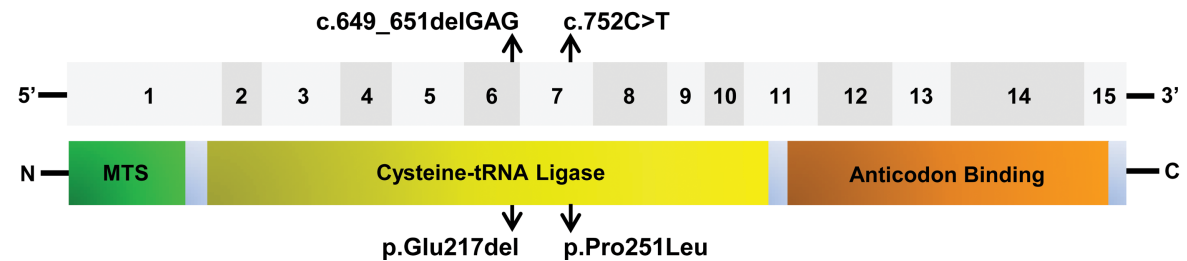

Figure 3 Pathogenic variants in CARS2. (A) Partial chromatograms showing Sanger sequencing results of CARS2 in the patient and his parents. The patient has an in-frame deletion (c.649_651delGAG, p.Glu217del) inherited from his father and a missense mutation (c.752C >T, p.Pro251Leu) inherited from his mother. (B) Comparative analysis of CARS2 proteins from multiple species demonstrated that Glu217 and Pro251 (highlighted in red) are evolutionarily conserved. Orthologs were identified by using BLASTP, and the alignments were performed by using ClustalW. Protein accession numbers are in parentheses. (C) Top panel shows the 15 exons of CARS2 CDNA as grey boxes. Bottom panel shows the CARS2 protein domains, including mitochondrial targeting sequence (MTS), the catalytic cysteine-tRNA ligase domain and the anticodon binding domain. Locations of variants are indicated by arrows. Paternal in-frame deletion is located in exon 6 and maternal missense mutation is located in exon 7. Both variants are located within the ligase domain of CARS2 protein. WT, wild-type.

between the aminoacyl-tRNA and the uncharged tRNA. A decrease of the ratio between the aminoacylated and deacylated form of mt-tRNA ${ }^{\mathrm{Cys}}$ was detected, whereas the aminoacylation of control mt-tRNAs, tRNA ${ }^{\text {His }}$ and tRNA ${ }^{\text {LeuUUR }}$ was normal (figure 4). Additionally, the steady-state levels of aminoacylated $\mathrm{tRNA}^{\mathrm{Cys}}$ were normal in the patient-derived sample compared with the controls (figure 4).

\section{Protein analysis and correction studies}

Western blot analysis was performed in cultured skin fibroblasts to analyse the effect of the CARS2 mutations on CARS2 protein levels. CARS2 was significantly reduced in the patient compared with controls (see online supplementary figure S4). To further confirm the role of CARS2 in the observed phenotype, we carried out retroviral transfection of normal CARS2 into the cultured skin fibroblasts from the patient. The full-length, wild- type CARS2 cDNA in a retroviral expression construct was introduced with high transfection efficiency (75\%, see 'Methods'). The additional bands resulting from incomplete assembly of complex $\mathrm{V}$ in patient's cultured skin fibroblasts on BN-PAGE were no longer visible after normal CARS2 cDNA transfection (figure 2C). This result indicated correction of the biochemical phenotype by the transfection with normal CARS2.

\section{CARS2 mutation screening}

Fifteen additional subjects with biochemical evidence of defects in mitochondrial transcription or translational were evaluated for CARS2 mutations. Sanger sequencing of all 15 coding exons and exon-intron boundaries of CARS2 did not identify potential pathogenic mutations. In order to potentially identify other subjects with a deficiency of CARS2, eight international mitochondrial and exome sequencing centres were contacted to evaluate 
Figure 4 Mitochondrial tRNA aminoacylation analysis by northern blotting. Northern blot analysis of mitochondrial tRNA aminoacylation in total RNA samples from the patient and control fibroblasts (control 1-control 3). Membranes were hybridised with radioactive tRNA probes as indicated. ' $\mathrm{dAc}$ ' indicates deacylated control sample. Densitometric quantification of the northern blots is shown on the right of each blot.
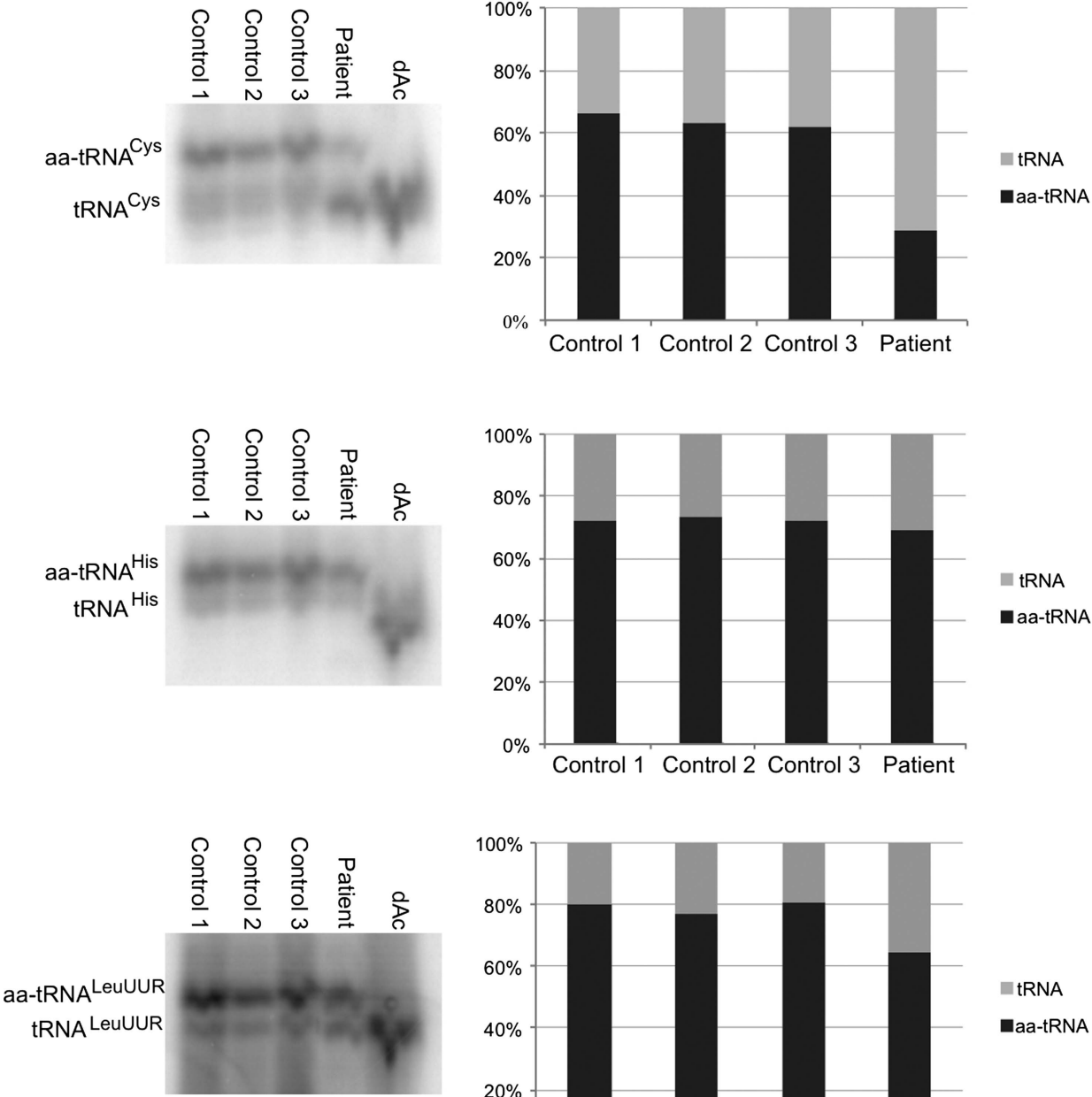

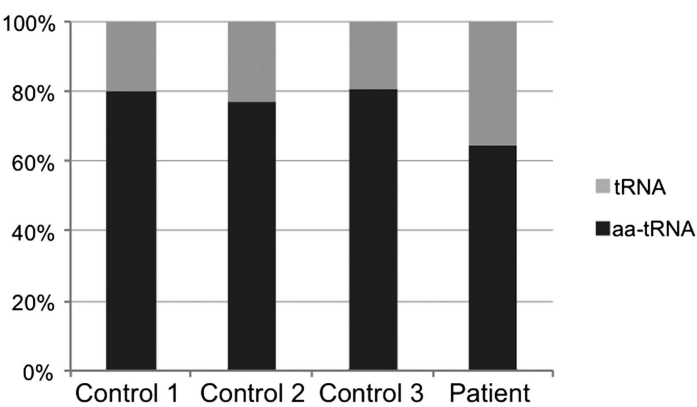

existing exome sequencing data. No other subjects with potential CARS2 mutations were identified.

\section{DISCUSSION}

Disorders of mitochondrial translation are an increasingly recognised cause of combined respiratory chain enzyme deficiency. ${ }^{25}$ Mitochondria possess their own translation machinery, which includes ribosomal and tRNAs encoded by mtDNA. In addition, mitochondrial translation requires nuclear encoded proteins including post-transcriptional tRNA modifiers, ARSs, mitochondrial ribosomal proteins, translation initiation factors, elongation factors and peptide release factors. ${ }^{25}$ To date, defects in 36 nuclear-encoded mitochondrial translation genes have been implicated in human disease (table 1).

ARSs are key enzymes in the translation of mRNA into proteins since they catalyse the specific attachment of each of the 20 amino acids to the corresponding tRNA. ARSs are ubiquitously expressed enzymes that are present in most species ranging from bacteria to humans. Because protein translation also occurs in the mitochondria, ARSs activity is required in these organelles. ${ }^{31}$ To facilitate their import, nuclear-encoded ARSs carry a mitochondrial targeting sequence within the mitochondrial ARSs (mt-ARSs) polypeptide. In total, 17 of the 37 nuclear-encoded ARSs genes including CARS2 are exclusively mitochondrial targeted, two are bi-functional in cytoplasm and mitochondria, whereas one of the mt-tRNA (Gln) is aminoacylated via an indirect pathway. ${ }^{32}$ Thus, the mutations in CARS2 detected in our patient, both of which are predicted to be deleterious, are likely to lead to defects in mitochondrial translation.

Leukodystrophy is a common finding in mt-ARSs deficiency, but the clinical spectrum also includes cardiomyopathy (AARS2), myopathy-lactic acidosis-sideroblastic anaemia (YARS2) and pontocerebellar hypoplasia (RARS2). ${ }^{33}$ The clinical phenotype in our patient was consistent with a severe mitochondrial epileptic encephalopathy with a complex movement disorder including severe oculogyric dystonia and mycolonus. Mild liver dysfunction with low albumin and steatosis has been noted in patients with POLG mutations. Defects in another mt-ARSs, FARS2, have also been associated with a very similar phenotype, which included fatal mitochondrial infantile-onset Alpers-like encephalopathy, ${ }^{35}$ and epileptic encephalopathy was also noted in a patient with mutations in VARS2. ${ }^{37}$ Recently, two siblings with severe myoclonic epilepsy and progressive cognitive decline were described with homozygous mutations in CARS2. ${ }^{38}$ These siblings presented at 9 and 5 years, respectively, and were reported to make academic progress prior to onset of symptoms. Our patient presented in the neonatal period, and the clinical course was marked by a complex movement disorder not described in the previous report. All of the patients thus far described have a complex and progressive epileptic disorder with global brain atrophy noted on MRI. The similarity between the phenotypes of the two siblings and our patient lends further support to the causality of the CARS2 mutations detected in our patient. 
Table 1 Nuclear-encoded genes associated with defects in mitochondrial translation

\begin{tabular}{|c|c|c|c|}
\hline Gene & OMIM & Function & Clinical symptoms \\
\hline AARS2 & 612035 & Aminoacyl-tRNA synthetase & Cardiomyopathy \\
\hline CARS2 & 612800 & Aminoacyl-tRNA synthetase & Mitochondrial encephalopathy \\
\hline DARS2 & 610956 & Aminoacyl-tRNA synthetase & Leukoencephalopathy \\
\hline EARS2 & 612799 & Aminoacyl-tRNA synthetase & Leukoencephalopathy \\
\hline FARS2 & 611592 & Aminoacyl-tRNA synthetase & Mitochondrial encephalopathy \\
\hline HARS2 & 600783 & Aminoacyl-tRNA synthetase & Ovarian dysgenesis, sensorineural hearing loss \\
\hline IARS2 & 612801 & Aminoacyl-tRNA synthetase & Cataracts, sensorineural hearing loss, encephaloneuromyopathy \\
\hline LARS2 & 604544 & Aminoacyl-tRNA synthetase & Ovarian dysgenesis, sensorineural hearing loss \\
\hline MARS2 & 609728 & Aminoacyl-tRNA synthetase & Ataxia \\
\hline NARS2 & 612803 & Aminoacyl-tRNA synthetase & Myopathy, encephalopathy \\
\hline RARS2 & 611524 & Aminoacyl-tRNA synthetase & Pontocerebellar hypoplasia \\
\hline SARS2 & 612804 & Aminoacyl-tRNA synthetase & Hyperuricemia, pulmonary hypertension, renal failure, alkalosis \\
\hline TARS2 & 612805 & Aminoacyl-tRNA synthetase & Mitochondrial encephalopathy \\
\hline VARS2 & 612902 & Aminoacyl-tRNA synthetase & Mitochondrial encephalopathy \\
\hline YARS2 & 610957 & Aminoacyl-tRNA synthetase & Myopathy, lactic acidosis, sideroblastic anaemia \\
\hline GFM1 & 606639 & Elongation factor & Hepatoencephalopathy \\
\hline TSFM & 604723 & Elongation factor & Encephalopathy, cardiomyopathy \\
\hline TUFM & 602389 & Elongation factor & Mitochondrial encephalopathy \\
\hline MTFMT & 611766 & Initiation and elongation factor & Leigh syndrome \\
\hline MRPL3 & 607118 & Mitochondrial ribosomal protein & Cardiomyopathy \\
\hline MRPL44 & 611849 & Mitochondrial ribosomal protein & Cardiomyopathy \\
\hline MRPS16 & 609204 & Mitochondrial ribosomal protein & Agenesis corpus callosum, lactic acidosis \\
\hline MRPS22 & 605810 & Mitochondrial ribosomal protein & Hypotonia, cardiomyopathy, tubulopathy \\
\hline C12orf65 & 613541 & Peptide release factor & Encephalomyopathy \\
\hline MTPAP & 613669 & Polyadenylation of mRNA & Spastic ataxia \\
\hline LRPPRC & 607544 & Post-transcriptional regulation & Leigh syndrome \\
\hline GTPBP3 & 608536 & Post-transcriptional tRNA modification & Cardiomyopathy, mitochondrial encephalopathy \\
\hline Мт01 & 614667 & Post-transcriptional tRNA modification & Cardiomyopathy \\
\hline PUS1 & 608109 & Post-transcriptional tRNA modification & Myopathy, lactic acidosis, sideroblastic anaemia \\
\hline TRIT1 & & Post-transcriptional tRNA modification & Mitochondrial encephalopathy \\
\hline TRMU & 610230 & Post-transcriptional tRNA modification & Liver failure, deafness \\
\hline ELAC2 & 605367 & Post-transcriptional tRNA processing & Cardiomyopathy \\
\hline HSD17B10 & 300256 & Post-transcriptional tRNA processing & Cardiomyopathy, mitochondrial encephalopathy \\
\hline PNPT1 & 610316 & RNA turnover (or RNA import) & Encephalomyopathy, deafness \\
\hline TACO1 & 612958 & Translation activation & Leigh syndrome \\
\hline RMND1 & 614917 & Unknown & Encephaloneuromyopathy \\
\hline
\end{tabular}

In several mt-ARSs defects, a very limited phenotype has been observed in the skin fibroblasts from patients, including normal respiratory chain enzyme activities, normal BN-PAGE gel analysis and normal mitochondrial translation assays. ${ }^{37} 3940$ However, the identification of a functional defect using BN-PAGE in the proband's cultured skin fibroblasts provided us a means to evaluate the causality of a novel gene through correction of the functional defect by transfection with the native gene and mitochondrial tRNA aminoacylation analysis by northern blotting. Furthermore, a mouse strain carrying homozygous missense mutations in Cars 2 appears to have neurological phenotypes including tremors, induced hyperactivity and head bobbing. ${ }^{41}{ }^{42}$ These neurological phenotypes in the mouse appear to be age-related and correlate well with the complex movement disorders and regression observed in our patient. The analysis of such model organisms at the organismal, tissue and cellular levels will lead to a better understanding of the role of CARS2 in the aetiology of the disease phenotype observed in our patient.

The identification of the genetic cause of severe mitochondrial infantile epileptic syndromes is difficult when mutations in
POLG and C10orf2 (TWINKLE) have been excluded. Often, the biochemical abnormalities are only present in liver despite minimal symptoms of liver dysfunction such as low albumin levels. Therefore, in patients with neurodegenerative disease, enzyme studies should include liver as well as skeletal muscle. ${ }^{43}{ }^{44}$ Defects in mitochondrial translation, particularly FARS2, VARS2 and CARS2, expand the known causes of this devastating condition.

In summary, we have identified compound heterozygous mutations in CARS2 in a patient with a combined respiratory chain enzyme deficiency using exome sequencing, followed by relevant functional studies to support the genetic finding. This report suggests that mutations in CARS2 are an important cause of a mitochondrial epileptic syndrome and highlights the important contribution of high-throughput sequencing in the genetic diagnosis of suspected mitochondrial disorders.

\section{Author affiliations}

${ }^{1}$ Department of Pediatrics, Section of Genetics, University of Colorado School of Medicine, Aurora, Colorado, USA

${ }^{2}$ Intellectual and Developmental Disabilities Research Center, University of Colorado School of Medicine, Aurora, Colorado, USA 
${ }^{3}$ Department of Pediatrics, Section of Clinical Genetics, Medical College of Wisconsin, Milwaukee, Wisconsin, USA

${ }^{4}$ Department of Pediatrics, Section of Neurology, University of Colorado School of Medicine, Aurora, Colorado, USA

${ }^{5}$ Department of Pediatrics, Division of Pediatric Neurology and Metabolism, Ghent University Hospital, Ghent, Belgium

${ }^{6}$ MRC Mitochondrial Biology Unit, Cambridge, UK

Twitter Follow Michal Minczuk at @mito_gene

Acknowledgements We are grateful to Ellen Elias and Cathlin Kucera for their input and advice on the clinical aspects of this project and for their contribution to patient care.

Contributors All authors fulfilled the criteria for authorship as defined by the International Committee of Medical Journal editors.

Funding This work was supported in part by funds from a grant to THS by the National Institutes of Health (GM081519) and funds and services from the Colorado Intellectual and Developmental Disabilities Research Center. The work was supported by Miracles for Mito to JVH, MWF and AEC. This work was supported in part by funds from a U01 grant from the National Institute of Diabetes, Digestive and Kidney Diseases (DK062453 [JVH]). This work was supported by the Medical Research Council, UK (MC_U105697135) for CAP and MM.

Competing interests None.

Patient consent Obtained.

Ethics approval IRB-approved research protocol (COMIRB \#07-0386) at the University of Colorado.

Provenance and peer review Not commissioned; externally peer reviewed.

\section{REFERENCES}

1 Skladal D, Halliday J, Thorburn DR. Minimum birth prevalence of mitochondrial respiratory chain disorders in children. Brain 2003;126:1905-12.

2 Koopman WJH, Willems PHGM, Smeitink JAM. Monogenic mitochondrial disorders. N Engl J Med 2012;366:1132-41.

3 Pagliarini DJ, Calvo SE, Chang B, Sheth SA, Vafai SB, Ong S-E, Walford GA, Sugiana C, Boneh A, Chen WK, Hill DE, Vidal M, Evans JG, Thorburn DR, Carr SA, Mootha VK. A mitochondrial protein compendium elucidates complex I disease biology. Cell 2008;134:112-23.

4 Vasta V, Ng SB, Turner EH, Shendure J, Hahn SH. Next generation sequence analysis for mitochondrial disorders. Genome Med 2009;1:100.

5 Haack TB, Haberberger B, Frisch E-M, Wieland T, luso A, Gorza M, Strecker V, Graf E, Mayr JA, Herberg U, Hennermann JB, Klopstock T, Kuhn KA, Ahting U, Sperl W, Wilichowski E, Hoffmann GF, Tesarova M, Hansikova H, Zeman J, Plecko B, Zeviani M, Wittig I, Strom TM, Schuelke M, Freisinger P, Meitinger T, Prokisch H. Molecular diagnosis in mitochondrial complex I deficiency using exome sequencing. J Med Genet 2012:49:277-83.

6 Calvo SE, Compton AG, Hershman SG, Lim SC, Lieber DS, Tucker EJ, Laskowski A, Garone C, Liu S, Jaffe DB, Christodoulou J, Fletcher JM, Bruno DL, Goldblatt J, Dimauro $S$, Thorburn DR, Mootha VK. Molecular diagnosis of infantile mitochondrial disease with targeted next-generation sequencing. Sci Trans/ Med 2012;4:118ra10

7 Sadleir LG, Connolly MB, Applegarth D, Hendson G, Clarke L, Rakshi C, Farrell K. Spasms in children with definite and probable mitochondrial disease. Eur J Neurol 2004;11:103-10.

8 Lee YM, Kang HC, Lee JS, Kim SH, Kim EY, Lee SK, Slama A, Kim HD. Mitochondrial respiratory chain defects: underlying etiology in various epileptic conditions. Epilepsia 2008:49:685-90.

9 Khurana DS, Salganicoff L, Melvin JJ, Hobdell EF, Valencia I, Hardison HH, Marks $H G$, Grover WD, Legido A. Epilepsy and respiratory chain defects in children with mitochondrial encephalopathies. Neuropediatrics 2008;39:8-13.

10 Harding BN. Progressive neuronal degeneration of childhood with liver disease (Alpers-Huttenlocher syndrome): a personal review. J Child Neurol 1990;5:273-87.

11 Wolf NI, Rahman S, Schmitt B, Taanman J-W, Duncan AJ, Harting I, Wohlrab G, Ebinger F, Rating D, Bast T. Status epilepticus in children with Alpers' disease caused by POLG1 mutations: EEG and MRI features. Epilepsia 2009;50:1596-607.

12 Gauthier-Villars M, Landrieu P, Cormier-Daire V, Jacquemin E, Chrétien D, Rötig A, Rustin $P$, Munnich A, de Lonlay P. Respiratory chain deficiency in Alpers syndrome. Neuropediatrics 2001:32:150-2.

13 Horvath $\mathrm{R}$, Hudson $\mathrm{G}$, Ferrari G, Fütterer N, Ahola S, Lamantea E, Prokisch H, Lochmüller H, McFarland R, Ramesh V, Klopstock T, Freisinger $P$, Salvi F, Mayr JA, Santer R, Tesarova M, Zeman J, Udd B, Taylor RW, Turnbull D, Hanna M, Fialho D, Suomalainen A, Zeviani M, Chinnery PF. Phenotypic spectrum associated with mutations of the mitochondrial polymerase gamma gene. Brain 2006;129:1674-84.
14 Sofou K, Moslemi A-R, Kollberg G, Bjarnadóttir I, Oldfors A, Nennesmo I, Holme E, Tulinius $\mathrm{M}$, Darin N. Phenotypic and genotypic variability in Alpers syndrome. Eur J Paediatr Neurol 2012;16:379-89.

15 Rahman S, Blok RB, Dahl HH, Danks DM, Kirby DM, Chow CW, Christodoulou J, Thorburn DR. Leigh syndrome: clinical features and biochemical and DNA abnormalities. Ann Neurol 1996;39:343-51.

16 Kendrick AA, Choudhury M, Rahman SM, McCurdy CE, Friederich M, Van Hove JLK Watson PA, Birdsey N, Bao J, Gius D, Sack MN, Jing E, Kahn CR, Friedman JE, Jonscher KR. Fatty liver is associated with reduced SIRT3 activity and mitochondrial protein hyperacetylation. Biochem J 2011;433:505-14.

17 Van Coster R, Smet J, George E, De Meirleir L, Seneca S, Van Hove J, Sebire G, Verhelst $H$, De Bleecker J Van Vlem B Verloo $P$ Leroy J. Blue native polyacrylamide gel electrophoresis: a powerful tool in diagnosis of oxidative phosphorylation defects. Pediatr Res 2001;50:658-65.

18 Smet J, Devreese B, Van Beeumen J, Van Coster R. Nondenaturing polyacrylamide gel electrophoresis as a method for studying protein interactions: applications in the analysis of mitochondrial OXPHOS complexes. Cell Biol 2005:4:259-64.

19 Smet J, Seneca S, De Paepe B, Meulemans A, Verhelst H, Leroy J, De Meirleir L, Lissens W, Van Coster R. Subcomplexes of mitochondrial complex $V$ reveal mutations in mitochondrial DNA. Electrophoresis 2009;30:3565-72.

20 Yu H-C, Sloan JL, Scharer G, Brebner A, Quintana AM, Achilly NP, Manoli I, Coughlin CR, Geiger EA, Schneck U, Watkins D, Suormala T, Van Hove JLK, Fowler $B$, Baumgartner MR, Rosenblatt DS, Venditti CP, Shaikh TH. An X-linked cobalamin disorder caused by mutations in transcriptional coregulator HCFC1. Am J Hum Genet 2013;93:506-14.

21 Hauenstein S, Zhang C-M, Hou Y-M, Perona JJ. Shape-selective RNA recognition by cysteinyl-tRNA synthetase. Nat Struct Mol Biol 2004;11:1134-41.

22 Vanlander AV, Menten B, Smet J, De Meirleir L, Sante T, De Paepe B, Seneca S, Pearce SF, Powell CA, Vergult S, Michotte A, De Latter E, Vantomme L, Minczuk M, Van Coster R. Two Siblings with Homozygous Pathogenic Splice Site Variant in Mitochondrial Asparaginyl-tRNA Synthetase (NARS2). Hum Mutat 2015;36:222-31.

23 Rorbach J, Minczuk M. The post-transcriptional life of mammalian mitochondrial RNA. Biochem J 2012;444:357-73.

24 Sylvester JE, Fischel-Ghodsian N, Mougey EB, O'Brien TW. Mitochondrial ribosomal proteins: candidate genes for mitochondrial disease. Genet Med 2004;6:73-80.

25 Smits P, Smeitink J, van den Heuvel L. Mitochondrial translation and beyond: processes implicated in combined oxidative phosphorylation deficiencies. J Biomed Biotechnol 2010;2010:737385.

26 Shutt TE, Shadel GS. A compendium of human mitochondrial gene expression machinery with links to disease. Environ Mol Mutagen 2010;51:360-79.

27 Kenmochi N, Suzuki T, Uechi T, Magoori M, Kuniba M, Higa S, Watanabe K, Tanaka T. The human mitochondrial ribosomal protein genes: mapping of 54 genes to the chromosomes and implications for human disorders. Genomics 2001:77:65-70.

28 Pearce S, Nezich CL, Spinazzola A. Mitochondrial diseases: translation matters. Mol Cell Neurosci 2013;55:1-12.

29 Nicholls TJ, Rorbach J, Minczuk M. Mitochondria: mitochondrial RNA metabolism and human disease. Int J Biochem Cell Biol 2013;45:845-9.

30 Antonellis A, Green ED. The role of aminoacyl-tRNA synthetases in genetic diseases. Annu Rev Genomics Hum Genet 2008:9:87-107.

31 Bonnefond L, Fender A, Rudinger-Thirion J, Giegé R, Florentz C, Sissler M. Toward the full set of human mitochondrial aminoacyl-tRNA synthetases: characterization of AspRS and TyrRS. Biochemistry 2005;44:4805-16.

32 Nagao A, Suzuki T, Katoh T, Sakaguchi Y, Suzuki T. Biogenesis of glutaminyl-mt tRNAGIn in human mitochondria. Proc Natl Acad Sci USA 2009;106:16209-14.

33 Riley LG, Cooper S, Hickey P, Rudinger-Thirion J, McKenzie M, Compton A, Lim SC, Thorburn D, Ryan MT, Giegé R, Bahlo M, Christodoulou J. Mutation of the mitochondrial tyrosyl-tRNA synthetase gene, YARS2, causes myopathy, lactic acidosis, and sideroblastic anemia--MLASA syndrome. Am J Hum Genet 2010;87:52-9.

34 Edvardson S, Shaag A, Kolesnikova O, Gomori JM, Tarassov I, Einbinder T, Saada A, Elpeleg 0. Deleterious mutation in the mitochondrial arginyl-transfer RNA synthetase gene is associated with pontocerebellar hypoplasia. Am J Hum Genet 2007:81:857-62

35 Elo JM, Yadavalli SS, Euro L, Isohanni P, Götz A, Carroll CJ, Valanne L, Alkuraya FS, Uusimaa J, Paetau A, Caruso EM, Pihko H, Ibba M, Tyynismaa H, Suomalainen A. Mitochondrial phenylalanyl-tRNA synthetase mutations underlie fatal infantile Alpers encephalopathy. Hum Mol Genet 2012;21:4521-9.

36 Almalki A, Alston CL, Parker A, Simonic I, Mehta SG, He L, Reza M, Oliveira JMA, Lightowlers RN, McFarland R, Taylor RW, Chrzanowska-Lightowlers ZMA. Mutation of the human mitochondrial phenylalanine-tRNA synthetase causes infantile-onset epilepsy and cytochrome c oxidase deficiency. Biochim Biophys Acta 2014;1842:56-64.

37 Diodato D, Melchionda L, Haack TB, Dallabona C, Baruffini E, Donnini C, Granata T, Ragona F, Balestri P, Margollicci M, Lamantea E, Nasca A, Powell CA, Minczuk $M$, Strom TM, Meitinger T, Prokisch H, Lamperti C, Zeviani M, Ghezzi D. VARS2 and TARS2 Mutations in Patients with Mitochondrial Encephalomyopathies. Hum Mutat 2014;35:983-9. 


\section{New loci}

38 Hallmann K, Zsurka G, Moskau-Hartmann S, Kirschner J, Korinthenberg R, Ruppert A-K, Ozdemir O, Weber $Y$, Becker F, Lerche H, Elger CE, Thiele H, Nürnberg $P$, Sander T, Kunz WS. A homozygous splice-site mutation in CARS2 is associated with progressive myoclonic epilepsy. Neurology 2014;83:2183-7.

39 Konovalova S, Tyynismaa H. Mitochondrial aminoacyl-tRNA synthetases in human disease. Mol Genet Metab 2013;108:206-11.

40 Schwartzentruber J, Buhas D, Majewski J, Sasarman F, Papillon-Cavanagh S, Thiffaut I, Sheldon KM, Massicotte C, Patry L, Simon M, Zare AS, McKernan KJ, FORGE Canada Consortium, Michaud J, Boles RG, Deal CL, Desilets V, Shoubridge EA, Samuels ME. Mutation in The Nuclear-Encoded Mitochondrial Isoleucyl-tRNA Synthetase IARS2 in Patients with Cataracts, Growth Hormone Deficiency with Short Stature, Partial Sensorineural Deafness, and Peripheral Neuropathy or with Leigh Syndrome. Hum Mutat 2014; 35:1285-9.
41 Eidenschenk C, Du X, Chong Y, Fan W, Frazen B, Elledge H, Kralli A, Evans R, Mueller U, La Vine D, Smart N, Schimmel P, Yang X, Beutler B. Record for madcow. Center for the Genetics of Host Defense, UT Southwestern, Dallas, TX. http:/l mutagenetix.utsouthwestern.edu (accessed 8 Jan 2014).

42 Eidenschenk C, Smart N, Beutler B. Madcow, a mutation in the mitochondrial cysteninyl-tRNA synthetase gene, results in an age-related neurobehavioral phenotype. MGI Direct Data Submission to Mouse Genome Database (MGD), MGI:4840539. http://www.informatics.jax.org (accessed 8 Jan 2014).

43 Garcia-Cazorla A, De Lonlay P, Rustin P, Chretien D, Touati G, Rabier D, Slama A, Saudubray JM. Mitochondrial respiratory chain deficiencies expressing the enzymatic deficiency in the hepatic tissue: a study of 31 patients. J Pediatr 2006;149:401-5.

44 Panetta J, Gibson K, Kirby DM, Thorburn DR, Boneh A. The importance of liver biopsy in the investigation of possible mitochondrial respiratory chain disease. Neuropediatrics 2005;36:256-9. 


\section{JMG}

Mutations in the mitochondrial cysteinyl-tRNA synthase gene, CARS2, lead to a severe epileptic encephalopathy and complex movement disorder

Curtis R Coughlin II, Gunter H Scharer, Marisa W Friederich, Hung-Chun Yu, Elizabeth A Geiger, Geralyn Creadon-Swindell, Abigail E Collins, Arnaud V Vanlander, Rudy Van Coster, Christopher A Powell, Michael A Swanson, Michal Minczuk, Johan L K Van Hove and Tamim H Shaikh

J Med Genet 2015 52: 532-540 originally published online March 18, 2015

doi: 10.1136/jmedgenet-2015-103049

Updated information and services can be found at:

http://jmg.bmj.com/content/52/8/532

Supplementary
Material

References

Email alerting service

\section{These include:}

Supplementary material can be found at:

http://jmg.bmj.com/content/suppl/2015/03/18/jmedgenet-2015-103049 .DC1

This article cites 42 articles, 8 of which you can access for free at: http://jmg.bmj.com/content/52/8/532\#BIBL

Receive free email alerts when new articles cite this article. Sign up in the box at the top right corner of the online article.

$\begin{array}{cc}\text { Topic } & \text { Articles on similar topics can be found in } \\ \text { Collections } & \text { Epilepsy and seizures (197) } \\ & \text { Genetic screening / counselling (886) } \\ & \text { Immunology (including allergy) (604) } \\ & \text { Metabolic disorders (329) } \\ & \text { Muscle disease (146) } \\ & \text { Neuromuscular disease (257) }\end{array}$

Notes

To request permissions go to:

http://group.bmj.com/group/rights-licensing/permissions

To order reprints go to:

http://journals.bmj.com/cgi/reprintform

To subscribe to BMJ go to:

http://group.bmj.com/subscribe/ 